\title{
Mais um anjo barroco?Uma revisão bibliográfica em antropologia da informação a partir de levantamento de textos através da ferramenta de busca Google
}

\section{Nísio Teixeira}

\section{Professor; Jornalista; Mestre e Doutorando em Ciência da Informação pelo PPGCI/UFMG; bolsista pela Capes.}

A partir de uma revisão teórica sobre o tema Antropologia da Informação, produziu-se um levantamento de textos sobre o tema através do instrumento de pesquisa Google, dos quais oito foram selecionados para verificar como cada um deles abordou a articulação entre antropologia e informação. Diversos no formato, extensão e abordagem, os textos partem de uma preocupação geral - como o ser humano, em seu processo cotidiano de produção de cultura, está envolvido, se relaciona e sofre o impacto das tecnologias de informação para seguir caminhos particulares: desde discutir como a antropologia pode ajudar a entender os especialistas em tecnologia da informação junto aos demais grupos que integram a esfera produtiva da 'cultura informacional', até discutir como, ao longo da história, as tecnologias de informação reconfiguraram e mesmo potencializaram o trabalho da antropologia. A revisão inclui ainda uma descrição da trajetória da antropologia e do conhecimento para o entendimento das relações sociais no ciberespaço; a combinação de metodologias das ciências sociais e da antropologia para o estudo de organizações hipermidiáticas e uma leitura da cibercultura à luz dos conceitos e idéias de Walter Benjamin. A diversidade dos resultados confirma as múltiplas diretrizes, apontadas na revisão teórica, para a discussão do tema na Ciência da Informação.

Palavras-chave: Antropologia da informação; Ciência da Informação e Cultura 


\section{Another baroque angel? A bibliographic review on anthropology of the information from texts searched on Google}

A theoretical review of Anthropology of the Information was the start point for a survey of texts using the Google search site. Eight texts were selected to verify how the relationship between anthropology and information was approached. These texts have diverse formats, lengths and approaches, but have a general concern - how the human being, in the daily process of culture production, is involved, how he relates and suffers the impact of the information technologies. Then, the texts have their particular characteristics: some discuss how anthropology can help to understand the specialists in information technology and those that integrate the productive sphere of 'information culture'; others discuss how, along the history, information technologies had reconfigured and also potentialized the work... of the anthropology itself! The review includes a description of the trajectory of anthropology and knowledge for the understanding of the social relations in the cyberspace; the combination of methodologies of social sciences and anthropology for the study of hypermedia organizations and review on cyberculture on the light of the concepts and ideas of Walter Benjamin. The diversity of these results confirms the multiple lines of direction, pointed by the theoretical review, for the discussion of this subject in Information Science.

Keywords: Anthropology of Information; Information.Science; Culture. passa a ser a seguinte: existirão tribos perdidas na web?"

(PATCHING e CHATHAM) 


\section{Introdução}

A princípio, olhando assim, meio de soslaio - ou seria senso comum? - pensar em antropologia da informação é pensar em algo conflitante, deslizante, que escorre sobre curvas barrocas. Afinal, de um lado a antropologia, que tende à compreensão da pluralidade, diversidade, multiplicidade de gestos, práticas, relatos. De outro, a informação, que tende à compressão, à homogeneização, tabulação, esquematização de gestos, práticas e relatos.

Por isso, falar em antropologia da informação remete a uma espécie de amálgama entre campos aparentemente antagônicos. Não cabe estabelecer aqui a trajetória de cada termo, mas é interessante perceber como a Antropologia, enquanto ciência, alcançou um estágio mais apurado na era moderna, exatamente na medida em que se desprendia de malabarismos etnocentristas para tentar fazer, não com os olhos do colonizador, mas do autóctone, uma leitura do mundo e das coisas do mundo. Da mesma forma, a informação, nos últimos anos, foi se desprendendo de um fator regulador de sistemas (físicos, químicos) para se tornar (e se integrar a) uma cultura informacional contemporânea e/ou pós-moderna (MARTELETO, 1987).

A partir de uma rápida consideração sobre estudo já desenvolvido na área da Antropologia da Informação, procuramos contribuir com o alargamento dessa revisão bibliográfica sobre o tema utilizando documentos disponíveis na internet através da ferramenta Google. Optamos por uma estratégia de verificação on line de textos recuperados, partindo da frase exata antropologia da informação (português) e anthropology of information (inglês) através da ferramenta de busca Google. No primeiro caso, verificou-se a ocorrência de 27 itens e, no segundo, 103, perfazendo um total de 130. Mas, para a presente revisão, a seleção considerou ainda um último aspecto: documentos cujos textos, além de relevantes, estivessem disponibilizados na íntegra para atender exatamente ao principal objetivo, que é o acesso e a ampliação - a partir do exame comentado de cada um dos oito textos selecionados - da discussão sobre Antropologia da Informação.

Dos oito textos selecionados (um baixo índice em relação à totalidade dos 130 documentos pertinentes à busca, menos de 10\%), quatro são artigos publicados em sites especializados; dois integram ementas de cursos e dois são papers (um para discussão na área, outro para políticas públicas1). Antes de prosseguirmos, cabe lembrar que, no

1 Os oito textos selecionados e analisados foram (a referência completa de cada um pode ser vista ao final deste trabalho): Ementas: 1)DIPLO. Anthropology of Information Society.2)KELTY, Christopher. Anthropology 315/515: Introduction to the Anthropology of Information and Networks; Papers: 3)HAKKEN, David. Knowledge, Cyberspace and Anthropology, 4)HARTMANN, Roger and SILVERSTONE, Roger. Emtel - European Media, Technology and Everyday Life Network: the user/producer interface e Artigos: 5)HOWARD, Philip. Network Ethnography and the Hypermedia Organization: new organizations, new media, new methods, 6)PAIVA, Cláudio Cardoso. Walter Benjamin e a Imaginação Cibernética: experiência e comunicabilidade na era do virtual, 7)PATCHING, Keith and CHATHAM, Rubina. The Anthropology of Information Technology in the $21^{\text {st }}$ Century e 8)ZEITLYN, David. Eletronic 
momento em que se lê esse artigo, nossa seleção, devido ao alto grau de atualização do Google através da incorporação de novos documentos, pode ter-se tornado ultrapassada. Mas pretendeu-se aqui apenas usar a ferramenta como forma de obter um recorte de textos que possam contribuir para o desdobramento de eventuais pesquisas ou, cumpre dizer, até mesmo para problematizações acerca da Antropologia da Informação.

\section{Uma revisão}

De acordo com Marteleto (2002), a antropologia da informação está sustentada por dois pressupostos: a informação como processo de elaboração de sentido, conectada às formas de representação do conhecimento (esfera da cultura); e como objeto de estudo de disciplinas, preocupadas em entendê-la como instância da organização e da permanência espacial e temporal, que gera memória e carece de meio, política e pedagogia (esfera da ciência, notadamente as ciências sociais e nela, evidentemente, a Ciência da Informação).

Conseqüentemente, segundo a autora, a antropologia da informação estabelece lógicas articuladas entre as instâncias do conhecimento, da informação e da sociedade, através da produção e interpretação de enunciados e da regência de gestos e ações. Essa dialética deve ser vista sob a ótica foucaultiana da ordem do discurso, a qual, por sua vez, para além do bordão conhecimento é poder, deve ser compreendida como: a) um sistema de nomeações (instrumentos para a ordem) e b)um conjunto de sujeitos e suas respectivas apreensões simbólicas.

Segundo a autora, três são os pressupostos gerais que formam uma agenda de estudos sobre o tema: 1)contextuais; 2)empíricos e 3)teóricos e metodológicos. Dentre os pressupostos contextuais, cabe destacar o do conhecimento como produto social, com o reconhecimento de uma "cultura informacional" e daqueles dela excluídos; o deslocamento do eixo de política de conhecimento e informação do estatal/público para o privado; e a conformação de um mercado de bens simbólicos com disputas de sentidos entre diferentes práticas, discursos e ações de intervenção social.

Dentre os pressupostos empíricos, destacam-se as diversas formas de organizações sociais e suas interfaces com ambientes formais de conhecimento e informação; o conhecimento teórico, histórico, prático e suas composições e estranhamentos na sociedade civil; ação social e saber local: especialistas, lideranças e intervenções com mediação informacional; informação formal dos sistemas oficiais $x$ informação cinzenta e/ou subterrânea das organizações.

Archives and Technology in Anthropological Research. Apenas um deles atendeu ao solicitado pela pesquisa em português. Em inglês, foram sete (nestes, todos os trechos e citações a serem apresentados futuramente são de tradução do autor deste artigo). É importante ressaltar que um mesmo texto teve às vezes duas e até mesmo oito ocorrências na busca do Google. 
Por fim, os pressupostos teóricos e metodológicos, interessados principalmente no estudo do conhecimento e na forma política e compartilhada de criar entendimento e soluções sobre as condições de vida da população nas práticas de intervenção social; a abordagem do conhecimento e da informação no plano local, da cultura e sua interdependência com o global, bem como dos elementos narrativos da memória e do esquecimento presentes nos modos de apreender as coisas do mundo vivido; o conhecimento como produto social e sua apropriação como matéria informacional pelos movimentos sociais; $e$, finalmente, 0 emprego crítico, teórico e metodológico da noção de redes, entendida aqui em três acepções: como conceito teórico, instrumento metodológico e estratégia de ação coletiva.

Em sua tese, Nanci Gonçalves da Nóbrega (2002) também resgata a proposta do eixo temático de pesquisa Antropologia da Informação, pertencente ao Programa de Pós-Graduação em Ciência da Informação MCT/IBICT - UFRJ/ECO. Tal proposta ajuda a visualizar ainda mais as perspectivas de ação junto a esse campo. Este núcleo temático tem como pressuposto teórico-metodológico geral a necessidade de ter o sujeito como fonte e eixo da problemática informacional, funcionando, portanto, no âmbito dos estudos de usuários, porém com um enfoque interdisciplinar mais ampliado. De acordo com a proposta, o objetivo geral do eixo foi o de construir um instrumento teórico e metodológico para o estudo das práticas sociais de produção, comunicação e recepção de informações, em diferentes campos e contextos sociais; de maneira a permitir um entendimento a seu respeito, bem como a propor linhas alternativas de ação institucional e de oferta e uso da informação, capazes de funcionar como facilitadoras do acesso, fluxo e aquisição dos conhecimentos produzidos socialmente. As temáticas privilegiadas pelo grupo de pesquisa são: [1] a informação como fenômeno sócio-cultural e seus modos de produção e organização em diferentes contextos organizacionais, comunitários e associativos da sociedade civil; [2] a informação e a construção do conhecimento pelos agentes, entidades e grupos em movimentos sociais de educação e saúde; [3] redes de movimentos sociais, redes de conhecimentos e a construção de sentidos para a ação social; [4] políticas e modos de gestão do conhecimento e informação na esfera da sociedade e o emprego das tecnologias de comunicação e informação; [5] conhecimento prático e conhecimento científico: novas configurações epistemológicas, lingüísticas e textuais na sociedade da informação. (NÓBREGA, 2002, p. 69)

Não por acaso, Marteleto (2002) destaca que a antropologia da informação denomina o modelo ocidental de conhecimento de cultura informacional, "uma vez que nela se separam e delimitam grupos de produtores, mediadores, receptores de informações, no contexto de um mercado de bens simbólicos, onde as informações, bens culturais, têm pesos e tarifas diferenciadas" (MARTELETO, 2002, p. 109-110).

No momento em que tal cenário se insere no âmbito de uma sociedade de massa, driblar a ideologia - canal privilegiado daquilo que 
Chomsky (1989) chamaria de a fabricação do consenso - e produzir conhecimento - no dizer de Melucci2, dentre outras características, a capacidade de análise, comunicação e reflexão - torna-se um recursochave para a ação coletiva. (MELUCCI, 2001 apud MARTELETO, 2002, p. 112).

Nesse cenário, como sugere Wainwright3, os movimentos sociais criam estratégias de intervenção social nas quais o estado surge "não como espécie de engenheiro externo, mas como um gerador potencial de uma estrutura democrática e de apoio público para uma série de formas de participação popular" (WAINWRIGHT, 1998 apud MARTELETO, 2002, p. 113). A própria ciência, historicamente construída para se opor ao chamado senso comum, retorna a ele em uma nova possibilidade de aliança mútua entre duas esferas do conhecimento.

\section{Textos selecionados}

\subsection{DIPLO. Anthropology of information society.}

Neste texto de quatro páginas tem-se acesso à ementa de um curso sobre Anthropology of Information Society, oferecido pela instituição. Apesar do número reduzido de páginas, o texto praticamente reforça alguns pontos e teses apresentadas no quadro teórico.

Segundo o texto, alguns dos problemas relacionados ao desenvolvimento da sociedade da informação estão profundamente enraizados na fruição cultural da informação de diferentes conteúdos, originários de várias fontes e apresentados de diferentes formas.

Fatores como a distribuição do poder, estrutura de relacionamento, sistema de valores predominantes, dentre outros, influenciam a forma na qual a informação é distribuída entre os membros de sua sociedade. Uma das principais diferenças que ocorre entre culturas é aquela relacionada à forma de estruturar a informação, o que significa que diferentes culturas utilizarão diferentes formas de gestão do conhecimento, de acordo com o emissor e o destinatário de alguma informação, pela maneira em que ela se apresenta, sua forma e conteúdo. Tais observações nos levam a concluir que um novo e frutífero filão de ciências preocupadas com a cultura, a antropologia em primeiro lugar, poderia se desenvolver; o que não apenas significa pesquisa da sociedade da informação no contexto de uma revolução em andamento nas tecnologias de comunicação e informação, mas que traz questões fundamentais acerca do monitoramento de informações em diferentes culturas (...). Esta orientação

2 MELUCCI, Alberto. A Invenção do Presente: movimentos sociais nas sociedades complexas. Petrópolis: Vozes, 2001.

3 WAINWRIGHT, Hillary. Uma Resposta ao Neoliberalismo: argumentos para uma nova esquerda. Rio de Janeiro: Jorge Zahar, 1998. 
fundamental de tal disciplina, que chamamos Antropologia da Sociedade da Informação, é um importante passo, já que o gerenciamento e a distribuição de informação via cabos e redes não vai mudar fundamentalmente a maneira pela qual os usuários finais decidem, em estruturas e funções sociais determinadas culturalmente, o processo de seleção e interpretação destas informações (DIPLO, 2004, p. 01)

O texto sugere que o conceito de semiosfera, desenvolvido por Yuri Lotman, se aplicaria muito bem ao cenário descrito acima. De forma similar à idéia de biosfera, tal conceito englobaria todo e qualquer fenômeno simbólico e, segundo o texto analisado, serviria para definir o campo de uma Antropologia da Ciência da Informação, entendida aí como uma disciplina preocupada com a dinâmica da distribuição, do processo e da recepção da informação, como uma função de variados elementos sócio-culturais na semiosfera.

Em seguida, a ementa pretende analisar quatro perspectivas de estudo: o conceito de informação em diferentes culturas, o controle da informação em diferentes culturas, a informação e as questões de gênero e a forma de network readiness (literalmente habilidade em rede, uma espécie de indicador de inclusão digital)4 em diferentes culturas.

Assim, em outro ponto interessante para o tema Antropologia da Informação, o texto comenta a primeira perspectiva sob curiosa proposta conceitual. Diz que uma definição formal de informação permanece a mesma em diferentes culturas da humanidade, a saber: informação "é aquilo que torna possível diferenças e escolhas" (DIPLO, 2004: p. 1). Assim sendo, a compreensão do significado de diferentes informações ao redor do mundo permanece diferente, dependendo justamente do contexto de vários fatores culturalmente determinados.

Por exemplo, se imaginarmos alguém que vive em uma cidade imaginária, na qual a chuva nunca pára de cair, o boletim meteorológico não é de forma alguma informação [para essa pessoa], porque não permite que nenhuma escolha possa ser feita sobre (e a partir) do boletim. Isso vai permanecer $o$ mesmo, independente da cultura produzida por esta cidade imaginária (...) Considere ainda a situação de alvorada em algum país polar, no qual o que se tem são dias e noites polares, e a situação em qualquer país longe de áreas polares.

4 Tal conceito foi desenvolvido recentemente pelos estudos em sociedade da informação e busca integrar os esforços para que uma determinada sociedade possa usufruir dos benefícios trazidos pela sociedade da informação. O Network Readiness Index (NRI), por exemplo, criado pela Universidade de Harvard, é um índice que quantifica o grau de infra-estrutura e educação tecnológica (especialmente acesso às redes) de um país. No biênio 2003/2004 o país que apresentou o maior NRI foi os Estados Unidos, com um índice de 5,5. Em segundo lugar veio Singapura, com 5,40. Seguem-se Finlândia, Suécia, Dinamarca, Canadá, Suíça, Noruega, Austrália e Islândia, com NRIs variando de 5,23 a 4,88. O país latino-americano melhor colocado é o Chile, em $32^{\circ}$ lugar, com um NRI de 3,94, seguido pelo Brasil, em $39^{\circ}$ com 3,67 (no biênio anterior estava em $38^{\circ} \mathrm{com}$ um índice de 3,79 ). A Argentina caiu do $32^{\circ}$ lugar para o $50^{\circ}$ e o Uruguai do $37^{\circ}$ para 0 540. Dados capturados do site http://www.bpiropo.com.br/em20040923.htm. Acesso em 07 de outubro de 2006. 
A mensagem o sol nasceu, nos países fora das áreas polares carrega pouca ou nenhuma informação, porque descreve um fenômeno diário que é completamente previsível. Por outro lado, de alguma forma podemos sentir que, nos países polares essa informação carrega mais informação, já que um típico alvorecer acontece uma vez ou outra! Em tais culturas, antropólogos podem esperar encontrar variados costumes relacionados a esses ciclos. (DIPLO, 2004, p. 01-02, grifo nosso)

Aqui o texto propõe uma agenda de estudos da Sociedade da Informação e suas influências para entender essa relação entre o conceito de informação e diferentes culturas: "(i) o que as pessoas de diferentes culturas acham mais interessante entre as informações que as cercam? ii) considerando as diferentes culturas, que tipo de informação é mais requisitado através da Internet? e iii) quais informações são mais valorizadas em diferentes sociedades?" (DIPLO, 2004, p. 02)

Em outro momento da ementa, discute-se não o conceito, mas como se dá o controle da informação em diferentes culturas. Partindo da perspectiva de Chomsky ou Foucault, esta inclusive apresentada rapidamente em nossa revisão teórica, um campo de investigação em antropologia da informação deve considerar que, por exemplo, o acesso às diferentes informações realmente produz poder social para aqueles que o tem. Em economia e política, a informação adequada no tempo certo é elemento essencial para qualquer ação de sucesso e, hoje, a informação em sociedade é controlada por diferentes formas de organização social do conhecimento.

O acesso à internet ao redor do mundo é um exemplo citado pelo texto, que destaca que o bloqueio de acesso ao Google na China é uma forma de controle do acesso à informação (ironicamente, complementaríamos, logo no país que produz boa parte dos equipamentos e produtos ligados à tecnologia da informação!). Aqui, uma agenda de estudos nesse campo, segundo o texto, poderia se basear nos seguintes itens/perguntas: i) quem controla a distribuição da informação nas diferentes sociedades?; ii) em diferentes culturas, qual é a relação das formas tradicionais de organização social (família, grupos, organização, estado, igreja, etc) com os meios de distribuição da informação?; iii) quem controla os meios de comunicação?; iv) quais são os mecanismos de controle dos meios de comunicação em diferentes culturas? Qual é o nível de censura aos meios de comunicação em diferentes sociedades? e v) qual é a relação entre o conhecimento e o poder em determinadas culturas? (DIPLO, 2004, p. 02-03)

A terceira perspectiva oferecida pelo texto diz respeito ao uso de informação por diferentes gêneros - termo aqui entendido como mais amplo do que a diferença sexual socialmente construída, englobando qualquer entidade social que constrói sua própria identidade em algum processo social. Procura entender e responder questões do tipo por que os negros têm pouco acesso à Internet, a partir da profunda compreensão de 
regras de compartilhamento de informação determinadas culturalmente entre os diferentes grupos de uma mesma sociedade; assim como sublinhar seus diferentes papéis nela. Assim, os problemas relacionados a essa perspectiva não dizem respeito somente às diferenças do acesso e do compartilhamento de informação entre homem e mulher, mas procura incluir outras entidades como crianças, terceira idade, "minorias", etc, em uma dada cultura. Aqui, uma agenda de questões/itens deve considerar: i) todos os diversos grupos sociais existentes em uma dada cultura têm igual acesso à informação?; ii) mulheres e homens são tratados eqüitativamente no processo de socialização e educação?; iii) existe alguma informação específica sobre os gêneros em uma dada cultura? Há algo estabelecido entre o que mulheres, crianças, homens, etc, devem ou não devem saber?; iv) existe alguma informação nacional específica [sobre algum grupo] em uma dada sociedade? Por exemplo, algum tipo de conhecimento que não deva ser compartilhado com "minorias" ou algum outro grupo social? (DIPLO, 2004, p. 03).

Por fim, o texto encerra apontando o modo como se processa a network readiness em diferentes culturas. Uma agenda de estudos nesse ponto deve considerar os seguintes itens/questões, além, é claro, da influência de fatores culturais sobre a sociedade da informação: i) Qual é o nível de alfabetização em uma cultura?; ii) Quais são atitudes sociais dominantes diante dos computadores e tecnologia da informação? e iii) Os sistemas educacionais são bem preparados para as mudanças geradas pelo desenvolvimento das redes globais? (DIPLO, 2004, p. 04)

\subsection{KELTY, Christopher. Anthropology 315/515: Introduction to the anthropology of information and networks.}

Ao contrário do texto anterior, a ementa de Kelty para uma Introdução à Antropologia da Informação e Redes é mais operacional do que teórica, e trata do tema apenas por tópicos, sem o nível de aprofundamento e detalhes oferecidos pelo site da Diplo. De toda forma, é interessante perceber que a linha de condução e aproximação entre os campos da antropologia e da informação recai sobre o seguinte: como as práticas cotidianas, e nelas, as dificuldades apresentadas por aparatos da tecnologia da informação (como o e-mail) atingem a esfera pública ou a ação individual subjetiva. A intenção é procurar um equilíbrio entre o computacional e o humano, sem o privilégio de um ou outro.

\subsection{HAKKEN, David. Knowledge, Cyberspace and anthropology.}

Em um texto de leitura densa, porém intrigante, o paper apresentado por David Hakken na reunião anual da American Anthropological Association em 2001 parte de uma perspectiva histórica para analisar as imbricações entre conhecimento, ciberespaço e 
antropologia. De novo, tem-se aqui uma tentativa de aproximação do campo da antropologia com o da informação a partir da emergência e do estudo sobre o conhecimento produzido nas redes ciberespaciais. O texto está interessado nos discursos sobre o conhecimento ocasionado pela variedade de tecnologia automatizada de informação e as mudanças sociais que o acompanham. Em seu artigo, Hakken vai, portanto, ficar mais preocupado em estabelecer uma antropologia do conhecimento.

Mais do que responder à questão do conhecimento no ciberespaço etnograficamente, temos que primeiro desenvolver com mais vigor uma antropologia do conhecimento (HAKKEN, 2001, p. 04).

Logo de início, o autor já deixa claro essa perspectiva, ao defender que o conhecimento reside em grupos, não em mentes individuais e que, mesmo em se tratando de um conhecimento em redes, tem-se diante de si um processo social. Hakken lembra que

está ficando por demais evidente, especialmente para aqueles que buscam utilizar o gerenciamento do conhecimento em organizações globalizadas - e nestes, em especial destaque para os que operam em múltiplas nações e/ou culturas - a busca por tecnologias que façam mais do que evitar a supressão de diferenças culturais: que reconheçam, cooperem e mesmo celebrem a diferença cultural. (HAKKEN, 2001, p. 05)

Se, de um lado, o uso da informação vem gradativamente pedindo maior flexibilidade quando confrontado com as práticas culturais, por outro lado, assinala o autor, os etnógrafos tendem a romper com uma certa visão binária (!) entre prática ocidental $x$ não ocidental, ou entre primitivo x moderno. Sabe-se que, em seu início, a antropologia atendia a uma espécie de busca pela essência cultural, muitas vezes de cunho etnocêntrico e racista, explicando, por exemplo, a supremacia branca européia em termos bioculturais. A moderna antropologia superou essa fase, buscando estabelecer-se dentro da tradição iluminista. Na contemporaneidade, contudo, Foucault critica a construção de uma antropologia do conhecimento. Para o filósofo francês, ela deve ser legitimada somente em seu próprio contexto cultural. Afinal, o conhecimento está entre os mais relativos fenômenos culturais, criado, comunicado e reproduzido localmente e com um caráter muito influenciado pela prática local.

A questão, para Foucault, não é destruir o conhecimento disciplinar, mas relativizá-lo como um instrumento para alternar as relações do poder; (...) é, simultaneamente, parte do perigo e uma ferramenta para combater o perigo" (HAKKEN, 2001, p. 07-08).

Assim, reconhecer a existência de um problema do conhecimento na antropologia é o primeiro passo. 
Hakken, citando Appadurai e Hannerz, lembra que, sendo um fenômeno moderno, a cultura frequentemente parece funcionar transnacionalmente, e não sob o enquadramento de um grupo geográfico qualquer. O autor sugere que uma etnografia do conhecimento pode investigar um grupo que compartilha formas e redes de conhecimento, como se ele dividisse uma cultura: se falamos de diferentes padrões de conhecimento, devemos evitar descrevê-los como tendo uma cultura. Hakken recorre a outro autor, Peter Worsley, para um exemplo sobre a sociedade aborígine:

eles não só têm vários conhecimentos sobre plantas e animais (...), como também formas sistemáticas, primeiro, de distinguir árvores e plantas de animais e, segundo, identificar, nos animais, se eles são de terra, rio ou mar, e criaturas que vivem no ar. Eles têm uma taxonomia quase não-religiosa, biológica - uma forma sistemática de classificar coisas (WORSLEY5 apud HAKKEN, 2001, p. 12)

Na seqüência, Worsley criticou o trabalho de Lévi-Strauss, que apontava para o pensamento aborígine como se fosse uma peça única. Worsley argumentou que havia várias formas de pensamento distintas; pelo menos, além da biológica, a religiosa, gastronômica, lingüística e mitológica. O que leva à idéia, já apresentada por Hakken, de que não há o Conhecimento, mas conhecimentos - mesmo nas sociedades mais primitivas ou, melhor dizendo, antigas. "Por isso uma antropologia do conhecimento (...) deve evitar a idéia do conhecimento como uma coisa, objeto ou commodity e buscar o processo social de sua criação" (HAKKEN, 2001, p. 14).

Em outra contribuição para seu estudo, Hakken recorre às idéias de Hendrik Sinding-Larsen, que articulou claramente a necessidade de um estudo específico da questão do conhecimento no ciberespaço com a necessidade de revitalizar o estudo da antropologia do conhecimento. $\mathrm{Na}$ verdade, Sinding-Larsen propõe uma antropologia da tecnologia da informação que enfocaria, etnologicamente, em diferentes padrões e, conseqüentemente, em diferentes práticas, a forma como a cultura avalia o conhecimento.

As novas tecnologias de informação têm alterado as condições de experiência e outros processos de aprendizado. Atualmente, esta tecnologia só afeta áreas muito limitadas do conhecimento (...). Uma forma de estudo comparada é clarificar a maneira na qual as várias formas culturais de gerenciamento de conhecimento estão relacionadas às várias formas de tecnologia de informação (...) Não é a primeira vez na história que uma nova tecnologia de informação tem alterado as regras para gerenciar o conhecimento (...) não

5 WORSLEY, Peter. Knowledges: culture, counterculture, subculture. The New Press: New York, 1997. 
podemos abrir mão do fato de que devemos compreender a estrutura para ficarmos aptos a continuar a operação (...) temos que possuir conhecimento tanto sobre a forma como sobre o processo. (SIDING-LARSEN6, 1984 apud HAKKEN, 2001, p. 15-16.)

O programa de Sinding-Larsen pretende verificar se e quando o conhecimento é externalizado, e se ele não é mais armazenado intracognitivamente - o que, lembra Hakken, é um ponto caro à análise da evolução cultural, em especial àquela proposta pela etnologia e pela etnografia.

O que observamos como conhecimento são tipicamente as estruturas que nos guiam quando nós levamos a cabo tarefas especializadas. Desde que estruturas puderam ser estocadas na forma escrita, não é necessário que nós nos lembremos de todas elas, podemos dar uma olhadinha sobre elas num livro e simplesmente seguir o texto. Mas nós não podemos escapar do fato de que nós devemos compreender a estrutura de forma a estarmos aptos a levar a cabo a operação (...) Devemos ter conhecimento tanto sobre a estrutura quanto sobre o processo (...) Isto não é o caso quando o conhecimento está estocado na forma de programas de computador. Neste caso, tanto a estrutura quanto o processo podem ser estocados e podemos ter operações levadas a cabo sem que nós, seres humanos, possamos compreender ou entender 0 que está acontecendo. $O$ processo de externalização torna-se mais completo. (SIDING-LARSEN, 1984 apud HAKKEN, 2001, p. 16, grifo nosso)

Hakken propõe, ao final de seu estudo, duas abordagens para uma antropologia do conhecimento no ciberespaço: 1) Identificar um conjunto de práticas como sendo "sobre" conhecimento, observá-las e analisá-las. Para fazê-lo, pode-se tentar operacionalizar um estudo definindo abstratamente algo que esteja próximo a uma prática que a torne "sobre" conhecimento. Contudo, conforme apontado por Whitehead, qualquer abordagem a priori poderia inevitavelmente distorcer o quadro emergente de um escopo geral de conhecimento. 2) Alternativamente, pode-se operacionalizar como sendo "sobre" conhecimento todas as coisas que os "nativos" dizem ser conhecimento. Esta abordagem parece ser encontrada em diversas contradições e silêncios nos discursos acerca do conhecimento das culturas atuais. (HAKKEN, 2001, p. 19)

Por fim, uma rápida referência a diversos trabalhos - inclusive o do próprio Hakken, ligado ao uso do software livre - dos quais destacaria as idéias de Mimi Ito, que prefere olhar para as redes como network

6 Hakken (2001) não apresenta a referência de SIDING-LARSEN, 1984. 
localities, nas quais a tecnologia é usada para construir comunidades baseadas em relações diferentes daquelas verificadas no lugar.

\subsection{HARTMANN, Roger and SILVERSTONE, Roger. Emtel - European Media, Technology and Everyday Life Network: the user/producer interface.}

A Emtel é uma rede estabelecida pela União Européia e é integrada por pessoas preocupadas com a mudança de local e significância das tecnologias e serviços de informação e comunicação no cotidiano, bem como com as implicações das mudanças técnicas associadas à revolução informacional para a vida cultural e social na Europa.

O foco inicial da Emtel é na interface entre o usuário e o produtor, na relação entre consumo e produção e nas implicações deste foco para uma compreensão da inovação das tecnologias de informação e comunicação. Nós problematizamos vários aspectos deste relacionamento, especialmente do ponto de vista que o considera como um processo social, cultural e comunicativo, bem como econômico. Uma preocupação central diz respeito ao papel do usuário na inovação tecnológica presente e futura. Processo torna-se uma palavra-chave na discussão, implicando em um contínuo e complexo movimento de objetos e significados tanto na vida (sic) das tecnologias de informação e comunicação, bem como no contexto de nossas vidas cotidianas (HARTMANN; SILVERSTONE, 1995, p. 01-02).

Dentre os pontos defendidos pela Emtel, dois vêm de encontro aos objetivos do presente trabalho: 1) como as tecnologias de informação e comunicação diferem de outras tecnologias, e quais implicações estas diferenças têm para compreensão de sua inovação, difusão e uso; 2) como as tecnologias de informação e comunicação são posicionadas no espaço cultural e social, e como seu significado social e cultural é afetado por fatores tecnológicos, econômicos e sociais. (HARTMANN; SILVERSTONE, 1995, p. 02)

A referência explícita ao termo antropologia da informação surge quando o documento discute o problema do poder e da política de informação. Aí a referência aparece precisamente no terceiro foco de conflitos que, segundo os autores, rege o poder e a política nessa área: conflitos envolvendo consumidores e outros consumidores7:

Aqui as diferentes dimensões de uma complexa sociologia e antropologia das tecnologias de informação e comunicação vêm à tona, com preocupações acerca do gênero, classe, idade, tipo de vida, região devendo ser consideradas para analisar tanto as linhas de batalha política como o relativo

\footnotetext{
${ }^{7}$ Os outros dois focos de conflito analisados por Hartman e Silverstone são, em primeiro lugar, os consumidores, usuários e o estado e, em segundo, os consumidores e os produtores.
} 
poder de seus participantes (HARTMANN; SILVERSTONE, 1995, p. 05)

O termo, conforme visto, aparece na verdade associado a uma "antropologia das tecnologias de informação", numa acepção bem próxima, conceitualmente falando, daquela descrita por Christopher Kelty e, em termos de ação, em consonância com a discussão desenvolvida na terceira perspectiva da Diplo, voltada para as questões de gênero/"minorias" diante das potencialidades das tecnologias de informação.

\subsection{HOWARD, Philip. Network Ethnography and the Hypermedia Organization: new organizations, new media, new methods}

Em seu extenso artigo, Philip Howard busca uma metodologia de análise para estudar as organizações hipermidiáticas. Por organizações hipermidiáticas ele se refere ao impacto que os novos meios de comunicação, principalmente através das tecnologias de informação, produziram nas organizações. Tal impacto pode ser mensurado através das seguintes características: 1) a emergência das redes; 2) a criação de um vasto conteúdo; 3) a simulação e rapidez de trocas, figurações e reconfigurações simbólicas.

Para compreender melhor o universo destas organizações hipermidiáticas, Howard anseia por uma metodologia que combine métodos qualitativos com análise sociológica - especialmente aquela voltada para grupos e redes. O resultado dessa combinação é o que o autor chama de Etnografia em Rede ou Network Etnography. De acordo com Howard, o aumento do envolvimento das pessoas, diariamente, com as novas tecnologias, pede ao pesquisador uma adaptação dos métodos existentes ao novo contexto sócio-cultural. O autor lembra que a etnografia se baliza pela descrição observadora do comportamento e da organização cultural. Partindo dessa premissa, ela pode analisar novas formas de organização, ainda que ancorada pelos conceitos de comunidades epistêmicas (Ciência Política), comunidades da prática (Sociologia) e redes de conhecimento (Administração). Em cada uma, o desafio é superar o determinismo organizacional (imposição de estruturas formais e hierarquias) e o determinismo tecnológico (imposição de uma estrutura de ferramentas de comunicação).

Tais erros têm uma explicação: resultam da aplicação de um método tradicional etnográfico para o estudo de padrões de interação social que são essencialmente aterritoriais (...) eles foram concebidos para o estudo de interações sociais específicas, centralizadas fisicamente e territorialmente (...) [enquanto que] tais comunidades não se formam ao redor de uma pessoa, centralizada, com lugar ou organização corpórea 
ou com o benefício da interação face-a-face de seus membros (HOWARD, 2002, p. 555).

Howard diz que a etnografia é um método para estudar o comportamento organizacional e a difusão social das novas mídias tecnológicas. Seu método rigoroso mergulha o pesquisador no quadro social e revela o mundano e o cotidiano. Nas tipologias de ação possível da etnografia, há quatro estratégias de amostragem: 1) variação, cujo foco recai nos atores e contextos relevantes; 2) extrema, na qual os casos inusuais estabelecem o usual; 3 ) bola de neve, no qual um informante leva ao outro e 4) teórica, que seleciona exemplos a partir das categorias de um modelo construído. "Quando o meio primário de interação é a internet, sabemos que as observações dos pesquisadores possuem um contexto off-line" (HOWARD, 2002, p. 559)

$\mathrm{Na}$ outra ponta da ação metodológica proposta pelo autor, estão as análises sociais das redes, as quais, da mesma forma que outros métodos quantitativos, são fortes na generalização teórica, mas fragilizadas por seu tratamento pouco reflexivo dos sujeitos, reduzindo relações sociais a valores mensuráveis. A idéia de Howard, uma proposta de etnografia em rede, busca exatamente combinar o uso dos métodos etnográficos de campo com a análise social das redes. Observação passiva ou ativa, imersão extensiva ou entrevistas em profundidade são conduzidas em múltiplos sites com subgrupos de interesse:

Em suma, a análise social das redes sozinha provavelmente não me revelaria uma comunidade para estudo, seus atores individuais não são ligados por uma forma organizacional ou proximidade física, mas são meramente uma coleção de indivíduos com interesses profissionais comuns em tecnologia e política. A etnografia, sozinha, possivelmente revelaria que há uma forte laço comunitário entre seus membros, mas não conseguiria um retrato do tamanho da comunidade, revelaria membros distantes ou exporia normas, regras e padrões de comportamento. A etnografia das redes produz dados culturais ricos sobre a idéia de trabalho em uma prática comunitária conectada, dados que poderiam ser situados entre os contextos de uma interação em micronível de um grupo até uma larga escala (...) com poucos riscos de produzir tecnológica ou organizacionalmente resultados deterministas. (HOWARD, 2002, p. 567).

O autor destaca, então, um estudo de caso de uma comunidade política eletrônica nos EUA, no qual reforça a importância de se criar uma metodologia própria para o estudo de espaços de trocas identitárias e culturais que se processam em um ambiente fragmentado e desterritorializado. 


\subsection{PAIVA, Cláudio Cardoso. Walter Benjamin e a Imaginação Cibernética: experiência e comunicabilidade na era do virtual.}

O texto propõe uma abordagem da cibercultura, colocando em perspectiva a experiência de agregação dos indivíduos pelas infovias, a partir de premissas e conceitos teóricos desenvolvidos por Walter Benjamin,...

[...] um filósofo que pensa o século XIX com as antenas ligadas na modernidade do século $X X$ (...) seus textos constituem uma ferramenta teórico-metodológica importante para uma antropologia da comunicação na perspectiva de uma Teoria Crítica (PAIVA, 2001, p. 01-02).

Uma das idéias de Benjamin, a do flanador solitário que passeia fascinado pelos objetos da grande cidade (mas esquivo ao espírito capitalista), redescoberto por Benjamin, na obra poética de Baudelaire, possui afinidades com a figura do internauta. O primeiro é um viajante atento e transeunte desconfiado que apreende o sentido dos objetos além da sua dimensão mercadológica: o segundo é um navegador curioso, cúmplice da agilidade, pesquisador interativo que busca nos objetos virtuais algo além da sua condição efêmera e transitória (PAIVA, 2001, p. 01-02)

Para o autor, pensar o coletivo e a Internet no contexto dos países em desenvolvimento remete a uma situação pouco resolvida entre a esfera pública e a esfera privada.

Hoje, quando há um visível declínio das formas de socialização (família, escola, sociedade civil, etc) os meios de comunicação, particularmente a Internet, enquanto instâncias de diálogo entre a intimidade e a publicidade, constituem veículos geradores de experiências interativas e de novas formas de sociabilidade. As noções de 'experiência e comunicação', para Benjamin, possuem um sentido convergente, isto é, traduzem a idéia de transmissão e partilha de uma mensagem; esta é uma das linhas mestras que norteiam nossa argumentação. (PAIVA, 2001, p. 02)

Segundo Paiva, as redes de informação estabelecem um novo parâmetro de discussão sobre integração e exclusão social; não somente porque apresenta a tribo dos sem micro, mas também porque a Internet pode integrar os excluídos em uma partilha coletiva.

Os paraísos artificiais da Internet relembram a utopia de uma 'felicidade do jardim público', forjada por Voltaire. Hoje, uma estratégia de comunicação social orientada por um projeto de 'cultivo ao jardim público' precisa enfrentar a nova desordem 
das relações entre o Estado, a sociedade, o mercado e as novas tecnologias. A discussão é inadiável e remete a um debate sobre a nova ordem internacional da informação, e num plano mais complexo, diz respeito às relações entre economia e política no contexto atual da mundialização (...) Caminhamos contra o vento num terreno considerado propício à evolução de tendências individualizantes e narcisistas, que é o espaço da realidade virtual. Contudo, ali encontramos formas de agregação e sociabilidade, atração coletiva, novos meios de territorialização e subjetividade ligados pelo sentimento dos indivíduos de pertencer a uma comunidade (PAIVA, 2001, p.03)

Três razões levaram o autor a este estudo, que relaciona Benjamim e a cibercultura: em primeiro lugar porque a expansão das máquinas de comunicar

coincide com a reaparição das representações religiosas, no fim de milênio, justo quando a racionalidade técnica parece reger a nova des-ordem do mundo. A reemergência do místico-religioso configura aquilo que alguns autores definem provisoriamente como um retorno do barroco, onde a razão e fé, a ciência e a mitologia, o sagrado e o profano, se reencontram. Isto permite compreender o computador de modo mais abrangente, ou seja, como instrumento técnico que calcula, quantifica e performatiza as estruturas do mundo pragmático, mas também como um novo tótem em torno do qual os indivíduos (e tribos) prestam reverência, cultivando-o como objeto sagrado, e que expressa a idéia de 'religação', comunhão e êxtase face à epifania das imagens geradas pelas redes [...] Depois porque a propagada 'crise dos paradigmas' [...] pode ser discutida à luz dos textos [do filósofo] sobre 'modernidades e modernos' [...] O singular na obra de Benjamin é despertar para a percepção da cultura no plural (sua parte material, mística, psicológica e social), mas sempre dirigida pela idéia de agregação coletiva. E finalmente [...] o seu conceito de aura e reprodução mecânica, as alegorias do anjo e da História, assim como as figuras do flanador, do colecionador ou da prostituta, a seu ver, não traduzem as formas de mercantilização, são antes expressões que condensam, simultaneamente, a dinâmica da vida material e emanação do espírito coletivo, a parte obscura e brilhante da vida (PAIVA, 2001, p.04).

O autor, de forma coesa, apresenta vários conceitos benjaminianos que comprovam sua hipótese. Recupera como características atuais, nos estudos de Benjamin, os mosaicos (que contaminam formas lingüísticas contemporâneas, do jornalismo aos videoclipes, sem falar nas 
homepages), a alegoria (estratégia de comunicação que permite flagrar o real em constante transformação), além do já citado flanador ("não encontrar o caminho numa cidade não é muito importante, mas perder-se numa cidade, como as pessoas se perdem numa floresta, exige prática" BENJAMIM8, 1987 apud PAIVA, 2001, p.9).

O flanador, o colecionador, o dândi, a prostituta e o apache são tipos sociais que o poeta encontra nas ruas de Paris, e me parecem arquétipos do homem que não virou suco em meio às engrenagens do sistema capitalista. Caminham, segundo Benjamin, num ritmo próprio. Reencontramos uma analogia da figura do flanador no estilo do internauta, que surfa na internet, zipando (comprimindo as informações num disquete e Ihes conferindo nova significação). Os objetos de consumo para o colecionador do século XIX como hoje, para o shoppista do século XX (em seu passeio pelas livrarias virtuais e fazendo compras on line), não indicam apenas o sintoma de uma reificação, alienação, mercantilização. São antes objetos de fruição estética, objetos de comunicação. Distintamente da lógica do burguês, os objetos para o colecionador, como para o internauta e o shoppista, são antes elementos de paixão, emoção, devoção, do que simples instrumentos utilitários (...) ali, o valor diletante supera o valor de uso. O dândi do século passado encontra a sua versão hoje, na expressão dos sujeitos que desprezam a TV, mas se deleitam numa viagem virtual pelos sites de museus excêntricos e das obras raras. Encontramos ainda os traços da prostituição nas salas eróticas, que constituem experiências de sensualidade num contexto mercadológico, mas que proporcionam o usufruto das interações prazerosas do sexo virtual (PAIVA, 2001, p. 13).

Após enfatizar outras características desta leitura atual benjaminiana, Paiva finaliza dizendo que,

às vésperas de um novo milênio, quando o tempo é transformado pela velocidade, reencontramos o Benjamin pensador do instante. A sua idéia de tratar o antigo como se fosse novo e o novo como expressão do antigo é algo estimulante e animador (PAIVA, 2001, p. 19).

\subsection{PATCHING, Keith and CHATHAM, Rubina. The Anthropology of Information Technology in the $21^{\text {st }}$ Century}

Também neste texto procura-se entender a antropologia da informação como a antropologia relacionada à tecnologia da informação

8 BENJAMIM, Walter. Infância em Berlim por volta de 1900. In: Obras Escolhidas - Rua de Mão Única. São Paulo: Brasiliense, 1987. vol. II. 
(TI). Da antropologia, os autores procuram destacar não o que ela ensina sobre a diversidade, mas sim sobre a similaridade, buscando padrões comuns utilizados por grupos, tais como a linguagem, contadores de histórias e lendas - procurando contextualizar a discussão para dentro do universo dos profissionais de TI. Não por acaso, aliás, abrem o texto com uma curiosa e divertida frase: "Se não há mais tribos perdidas no Amazonas, a questão torna-se a seguinte: existirão tribos perdidas na web?" (PATCHING e CHATHAM, 1999, p. 01).

O tom irônico e direto, aliás, perpassa todo o texto, dedicado a buscar características generalizadas - conforme frisam - acerca das pessoas de $\mathrm{TI}$, correndo o risco, mas ao mesmo tempo o desafio, de uma estereotipização.

Estereotipar não é moralmente bem-vindo nos tempos politicamente corretos da cultura ocidental; mas é o mesmo fenômeno mental que permitiu aos nossos antepassados reconhecer o perigo em um instante e viver o bastante para se proliferar. Pedir um tempo para checar a validade de primeiras impressões pode ser fatal na natureza (PATCHING e CHATHAM, 1999, p. 02)

Dentre as características do estereótipo de uma pessoa de TI, está seu conforto em relação à lógica, aos fatos e dados, mas também o seu significante desconforto em relação ao que é ambíguo e imprevisível. Seu mundo é preto-e-branco e qualquer tom de cinza é rejeitado. De acordo com o estereótipo, uma pessoa de TI não é imaginativa, nem pensa criativamente. São pobres ao lidar com dilemas morais ou éticos e evitam tomar decisões nas quais não existam prováveis respostas em sim ou não. Assim, ao invés de, talvez, entendê-los como tribo, talvez fosse mais correto referir-se a eles como xamãs. Não são propriamente uma tribo distinta, mas aqueles que têm um papel especial na mesma.

Eles aprendem dialetos estranhos e, quase sempre, incompreensíveis, são tratados com um certo mix de medo e desprezo por seus poderes e por seu freqüente comportamento anti-social. Muitos deles não têm permissão para casar ou aproveitar prazeres normais de socialização, trancam em si mesmos até que são chamados para curar ou, ainda, lidar com algum desastre natural [do mundo da TI]. Quando surgem, seu comportamento é imprevisível [...] Muitos de seus cultos são possíveis mediante o uso de drogas. (PATCHING e CHATHAM, 1999, p. 02)

Portanto, ao contrário de apontamentos anteriores, os autores tentam menos visualizar como a TI influencia na prática cultural cotidiana de grupos diversos, e enfocam mais uma possível identidade da comunidade dos próprios profissionais proponentes envolvidos na produção e construção de TI. 


\subsection{ZEITLYN, David. Bica On line: eletronic archives and technology in anthropological research}

O texto comenta o lançamento, em versão on line a ser disponibilizada via internet, do The Bulletin of Information on Computing in Anthropology (Bica), publicado entre os anos de 1984 e 1988. A partir desse gancho, aborda rapidamente, embora de maneira interessante, o impacto das tecnologias de informação e comunicação no fazer antropológico.

Não acho fácil traçar um paralelo entre o status da computação junto à antropologia hoje com aquele da fotografia e do filme no início dos anos 60 . O desenvolvimento tecnológico de aparelhos como pequenas câmeras portáteis e, mais importante, o gravador cassete portátil tiveram implicações radicais na condução da pesquisa antropológica, apesar desse aspecto ser raramente discutido nas publicações. A tecnologia do computador agora facilita a publicação e disseminação de dados em uma escala anteriormente impossível. Sons e imagens podem ser transmitidos na Internet ou em um disco, bem como um texto. Contudo, os computadores podem fazer mais do que simplesmente transmitirem imagens (ZEITLYN, 2004, p. 01).

Dentre as possibilidades computacionais, o autor inclui desde o impacto do uso de e-mail nas pesquisas antropológicas, até a construção de modelos demográficos nos computadores, sem mencionar o uso da Internet como plataforma simultânea de pesquisa e distribuição.

\section{Conclusões}

Considerando o quadro teórico apresentado, é muito interessante perceber como os oito artigos selecionados perpassam, por exemplo, todos os três pressupostos elencados por Marteleto (2002), para reforçar a proposta de uma agenda de estudos na área da Antropologia da Informação, especialmente no que diz respeito às implicações políticas e econômicas e, principalmente, à discussão sobre a idéia das redes. Convém ressaltar que os textos foram obtidos através de uma pesquisa utilizando a ferramenta de busca Google, não foi feita diretamente sobre uma base de dados on line ou site referência especializado sobre a área mas que considerou documentos disponibilizados, na íntegra, pela Internet.

Conforme salientado no início da análise, se há um eixo comum que perpassa textos aparentemente distintos como os aqui apresentados, é a preocupação em entender como fica ou transcorre a prática cotidiana de trocas simbólicas sob o impacto das tecnologias e da sociedade da informação. Cada texto analisado, ao seu modo, procurou entender, nessa perspectiva, possíveis contribuições da antropologia (e 
consequentemente, da etnografia e da etnologia) para o quadro atual de produção, circulação, processamento e recepção da informação (e consequentemente, da comunicação e do conhecimento).

Logo de início pôde-se ver que um texto como o da Diplo quer ir além da simples análise de como as tecnologias da informação -TIinfluenciam o cotidiano das pessoas, mas, sob uma perspectiva mais ampla, propõe uma antropologia da informação que visa entender como as TI operam, entre sujeitos e instituições, em toda a forma de troca simbólica. Avançando em outra constatação que pode enriquecer o debate sobre o tema, teríamos que, enquanto a antropologia tende a recair sobre o que é domínio do ordinário (por exemplo, entender a prática cultural cotidiana de um grupo), a informação tende a recair sobre o que é domínio do extraordinário (permitir escolhas distintas) - conforme visto no exemplo da cidade imaginária da chuva eterna.

Em alguns autores - Diplo, Hakken e, mais evidentemente, Howard, - há correlação com o pensamento e a crítica de Michel Foucault. Uma antropologia da informação corre o risco de ser incorporada a uma ordem discursiva dominante, mas pode também ser instrumento e ferramenta para desconstruir ou questionar essa mesma ordem ou fabricação de consensos (Chomsky). Grande referência na retórica sofista, Górgias, já na Grécia antiga, defendia que "verdade é tudo aquilo que convém a quem detém o poder de convencimento". Pelos artigos apresentados, uma antropologia da informação pode descrever o cenário e as práticas, e apontar uma verve crítica que desmascare novos Górgias e/ou abordagens neosofistas.

Ao mesmo tempo, Hakken, Howard e Paiva procuram entender, de forma mais ampla, uma preocupação denunciada em Kelty: como ficam as trocas de identidade, simbólicas e mesmo informativas nos ambientes virtuais - sejam eles usuários e participantes do ciberespaço, das comunidades hipermidiáticas ou da cibercultura? Certamente são tópicos indispensáveis para estudos em antropologia da informação aos quais os três autores dão pistas e recomendações preciosas para abordagem e análise.

Kelty, entretanto, propõe que uma antropologia da informação possa investigar como as tecnologias de informação podem afetar as práticas cotidianas, tanto públicas como privadas (a preocupação sobre a dicotomia do público e do privado, aliás, foi constante em vários dos textos analisados). Nesse ponto, temos duas contribuições, quase que insights postos no papel: o impacto das TI no comportamento da 'tribo' (ou xamãs) dos profissionais da própria TI (Patching e Chatham), bem como Zeytlin, que denuncia a pouca ou quase nenhuma discussão sobre como as tecnologias da informação afetaram e/ou contribuíram para a própria evolução do método antropológico.

Uma contraposição interessante ao nosso estudo seria aplicar os mesmos princípios verificacionais e o termo analisado em uma base de dados especializada; proposta que pode gerar um interessante trabalho futuro e complementar ao aqui apresentado - que, afinal, se configura, 
ele próprio, um exemplo dos conceitos benjaminianos de 'mosaico' e 'alegoria', apresentados por Paiva. Tal bricolagem de idéias e pistas para contribuição na área de Antropologia da Informação, reunindo textos e apontamentos (no máximo interessantes, no mínimo curiosos), permitirá um novo incremento à discussão sobre o tema.

Assim, pelo menos do ponto de vista dos textos aqui apresentados, pode-se pensar numa proposta de agenda de estudos em antropologia da informação que constitua um campo apto a analisar: 1)o estudo da informação como parte das trocas simbólicas entre grupos; 2)como diferentes culturas/segmentos sociais se apropriam de e interagem com as tecnologias de informação e 3)o impacto das tecnologias de informação no processo de construção do conhecimento (inclusive do fazer científico).

No início deste trabalho, apontamos um caráter conflitante, "que escorre sobre curvas barrocas" para tentar entender a combinação entre antropologia e informação, dado, a princípio, o caráter antagônico de ambos. Ao final, podemos dizer que este estudo ajudou neste amálgama barroquista entre a Antropologia e a Informação. Afinal, indo mais além, dizia o teólogo, filósofo e cientista Emanuel Swendenborg, quando um homem e uma mulher se aproximam e se amam muito na Terra, uma vez no Céu, os dois, juntos, formam um só Anjo. O nosso segue em ascensão, barroco, e, oxalá, sob as bênçãos de um benjamin.

\section{Referências}

BENJAMIM, W. Infância em Berlim por volta de 1900. In: Obras Escolhidas - Rua de Mão Única. São Paulo: Brasiliense, 1987. vol. II apud PAIVA, Cláudio Cardoso. Walter Benjamin e a imaginação cibernética: experiência e comunicabilidade na era do virtual. Biblioteca On-line de Ciências da Comunicação. Recife: UFPB, 2001. Disponível em $<$ www.intercom.org.br/papers/1999/gt16/61in.pdf $>$. Acesso em: 15 jul. 2004. Também disponível em: <http://www.bocc.ubi.pt/pag/cardosoclaudio-paiva-walter-benjamin.pdf.> Acesso em: 29 out. 2007.

CHOMSKY, N. Manufacturing Consent. Boston: South End Press, 1989.

DIPLO. Anthropology of Information Society. Disponível em: $<$ http://textus.diplomacy.edu/portals/isanthropology/oview.asp?FilterTopi $\mathrm{c}=\% 2 \mathrm{~F} 45464>$. Acesso em: 15 jul. 2004.

HAKKEN, D. Knowledge, Cyberspace and Anthropology. 2001. Disponível em: <www.knowledgenet.org/papers/01aaapaper01.pdf>. Acesso em: 15 jul. 2004.

HARTMANN, R.; SILVERSTONE, R. Emtel - European Media, Technology and Everyday Life Network: the user/producer interface. 1995. Disponível em: <www.emtel2.org/>. Acesso em: 15 jul. 2004.

HOWARD, P. Network Ethnography and the Hypermedia Organization: new organizations, new media, new methods. 2002. Disponível em: 
$<$ www.memestreams.net/users/jlm/blogid1785198>. Acesso em: 15 jul. 2004.

KELTY, C. Anthropology 315/515: introduction to the anthropology of information and networks. Disponível em <www.kelty.org/or/classes/anth315.01.pdf>. Acesso em: 15 jul. 2004.

MARTELETO, R. M. Informação: elemento regulador dos sistemas, fator de mudança social ou fenômeno pós-moderno? Ciência da Informação, v. 16, p. 169-180, jul./dez. 1987.

Conhecimento e Sociedade: pressupostos da antropologia da informação. In. AQUINO, M. de A. (Org.). O Campo da Ciência da Informação: gênese, conexões e especificidades. João Pessoa: Editora Universitária, 2002. p. 101-115.

MELUCCI, A. A Invenção do Presente: movimentos sociais nas sociedades complexas. Petrópolis: Vozes, 2001 apud MARTELETO, R. M. Conhecimento e Sociedade: pressupostos da antropologia da informação. In. AQUINO, M. de A. (Org.). O Campo da Ciência da Informação: gênese, conexões e especificidades. João Pessoa: Editora Universitária, 2002. p. 101-115.

NÓBREGA, N. G. Conjugando o Gerúndio: antropologia da informação e leitura - percursos de leitor. 2002. Tese (Doutorado em Ciência da Informação) Universidade Federal do Rio de Janeiro - UFRJ. Rio de Janeiro: Ibict/MCT, 2002.

PAIVA, C. C. Walter Benjamin e a imaginação cibernética: experiência e comunicabilidade na era do virtual. Biblioteca On-line de Ciências da Comunicação. Recife: UFPB, 2001. Disponível em <www.intercom.org.br/papers/1999/gt16/61in.pdf $>$. Acesso em: 15 jul. 2004. Também disponível em: <http://www.bocc.ubi.pt/pag/cardosoclaudio-paiva-walter-benjamin.pdf. > Acesso em: 29 out. 2007.

PATCHING, K.;CHATHAM, R. The Anthropology of Information Technology in the $21^{\text {st }}$ Century. 1999. Disponível em: <http://www.itanalysis.com/researcharchivepdf.php?id=99>. Acesso em: 15 jul. 2004.

SIDING-LARSEN, 1984 apud HAKKEN, D. Knowledge, Cyberspace and Anthropology. 2001. Disponível em: $<$ www.knowledgenet.org/papers/01aaapaper01.pdf $>$. Acesso em: 15 jul. 2004.

WAINWRIGHT, H. Uma Resposta ao Neoliberalismo: argumentos para uma nova esquerda. Rio de Janeiro: Jorge Zahar, 1998 apud MARTELETO, R. M. Conhecimento e Sociedade: pressupostos da antropologia da informação. In. AQUINO, M. de A. (Org.). O Campo da Ciência da Informação: gênese, conexões e especificidades. João Pessoa: Editora Universitária, 2002. p. 101-115.

WORSLEY, P. Knowledges: culture, counterculture, subculture. The New Press: New York, 1997. 
ZEITLYN, D. Bica On line: electronic archives and technology in anthropological research. Disponível em: <http://lucy.ukc.ac.uk/bicaweb/bica intro.html>. Acesso em: 15 jul. 2004. 